\title{
Bioactive Amento flavone isolated from Cassia fistula L. leaves exhibits therapeutic efficacy
}

\author{
M. Srividhya ${ }^{1,2} \cdot$ H. Hridya ${ }^{1} \cdot$ V. Shanthi ${ }^{1} \cdot$ K. Ramanathan ${ }^{1}$
}

Received: 18 October 2016/Accepted: 2 January 2017/Published online: 11 April 2017

(c) The Author(s) 2017. This article is an open access publication

\begin{abstract}
Novel natural compounds endowed with sound bioactivities are currently the utmost need as leads toward drug discovery. For the first time, here, we report the presence of Amentoflavone (biflavonoid) in the leaves of Cassia fistula L. Structural characterization was carried out using ultraviolet-visible spectrophotometer, Fourier transform infrared, nuclear magnetic resonance, and thin-layer chromatography. The isolated compound was further evaluated for its bioactivity. The compound demonstrated moderate cytotoxicity in liver carcinoma (HepG2) cells, and the comparative analysis for the standard and normal compound has also been validated. Antioxidant potential was assessed by DPPH assay. Furthermore, efficacy of the compound in the aforesaid assays asserts its bioactivity and subsequently its importance as a potent therapeutic. Our study strongly suggests that Amentoflavone present in the leaf extracts of $C$. fistula L. definitely holds promise in the pharmaceutical industry.
\end{abstract}

Keywords Cassia fistula L. · Amentoflavone · Biflavonoid · Antioxidant · Cytotoxicity

K. Ramanathan

kramanathan@vit.ac.in

1 Department of Biotechnology, School of Bio Sciences and Technology, VIT University, Vellore, Tamilnadu 632014, India

2 Karpaga Vinayaga College of Engineering and Technology, Chinnakolambakkam, Kanchipuram Dt, Madhurantagam, India

\section{Introduction}

The use of plants and their constituents in primary health care has ancient history as old as human beings. Various medicinal plants have proven therapeutics implication in the health management via antioxidant, anti-inflammatory, anti-diabetic, and other biological activities (Rahmani et al. 2014a, 2014b; Rahmani and Aly 2015). Cassia fistula L. (Caesalpiniaceae) is commonly called Indian Laburnum and is native to India, Amazon, Sri Lanka, and extensively available in various countries, including Mauritius, South Africa, Mexico, China, West Indies, East Africa, and Brazil (Bahorun et al. 2005; Rajagopal et al. 2013). The main medicinal property of $C$. fistula $\mathrm{L}$. is mild laxative suitable for children and pregnant women. It is also used as a purgative due to the wax aloin and a tonic and has been reported to treat many intestinal disorders, such as ulcers (Bhalodia et al. 2012). In the Indian literature, this plant has been described to be useful against skin diseases, liver troubles, tuberculosis glands, and its use in the treatment of hematemesis, pruritus, leucoderma, and diabetes and has also been suggested that $C$. fistula has anti-microbial and anthelminthic properties (Vasudevan et al. 2009; Panda et al. 2011; Siva 2007) and also possesses significant hepatoprotective activity (Das et al. 2008). C. fistula extract is used as an anti- periodic and anti-rheumatism, and the leaf extract is also indicated for its antitussive and wound healing properties (Senthil kumar et al. 2006). The several species of Cassia are known to produce a variety of phenolic metabolites with novel structures, especially flavonoids. Therefore, the objective of the study was to investigate the novel compound and their bioactivity in leaves of $C$. fistula. For the first time, a novel Amento flavonone has been identified in the leaves of $C$. fistula by systematic bioassay-guided fractionation of the ethanolic 
extract. The therapeutic efficacy of Amento flavonone has been reported in this paper through DPPH and cytotoxicity to HepG2 (human hepatic carcinoma) cell line. The present study explores the role of the novel compound obtained from the leaves ethanolic extract of $C$. fistula. To the best of our knowledge, this is the first report on Amento flavonone from Cassia fistula $\mathrm{L}$.

\section{Materials and methods}

\section{Plant material}

Leaves of $C$. fistula Linn. were collected from Madhurantagam village, Kanchipuram District, Tamil Nadu, India and subsequently maintained as a herbarium sample with a voucher number PARC/2015/3071. The samples were cleansed thoroughly in water, air dried and ground into semi-granulated powder to be used for further processing.

\section{Preparation of extract and isolation}

The fresh leaves about $60 \mathrm{~g}$ was subjected to exhaustive extraction in a soxhlet apparatus using $100 \%$ ethanol $(250 \mathrm{ml})$ as a solvent. This extracts, referred to as the crude extract here onwards, yielded an extract of $2.5 \mathrm{~g}$. Thereafter, $1 \mathrm{~g}$ of dried ethanolic crude extract was subjected to column chromatography with $30 \mathrm{~g}$ silica gel (60-120 mesh). In column, hexane with silica gel was poured into the column and gradually added slurry. The fraction was eluted from the crude extract with hexane and ethyl acetate (4:1). Fractions obtained from column chromatography were checked individually, and identical fractions were pooled together based upon the TLC band. This process continued until we obtain minimum compound with maximum purity.

\section{Phytochemical characterization}

The yielded compound is semisolid (20 mg), and the absorbance wavelength of isolated molecules was analyzed using UV-Vis spectrophotometer (Systronics AU-2401 UV-Vis double beam spectrophotometer). The spectral values of the isolated compound were identified with the peak obtained in the spectral range of $250-400 \mathrm{~nm}$. FTIR analysis was carried out using a Shimadzu IR Affinity-1 Fourier transform infrared spectrophotometer. Spectra were collected and treated using the OMNIC software. ${ }^{1} \mathrm{H}$ and ${ }^{13} \mathrm{C}$ NMR spectra were determined in $\mathrm{CDCl}_{3}$ solution at $400 \mathrm{MHz}$ using Bruker Ascend Model. All spectra were recorded on a Bruker AC-250 spectrometer at $5.87 \mathrm{~T}$ (250.133 and $62.896 \mathrm{MHz}$ ). The compound was dissolved in CD3OD (99.8\% D) and estimated as per the standard protocol. Amentoflavone present in the sample was identified by matching the retention time against those of the standard, and the content of Amentoflavone was determined using calibration curve. The data analysis was done using the Empower 2 software.

\section{DPPH scavenging activity}

The ability of the isolate to scavenge free radicals was confirmed by estimation of its DPPH radical scavenging activity, as described by Ohinishi et al. (1994). Five different concentrations $(6,12,25,50$, and $100 \mu \mathrm{g} / \mathrm{ml})$ of the pure compound were prepared. To each, $3 \mathrm{ml}$ of DPPH $(0.1 \mathrm{mM} / \mathrm{ml}$ in ethanol) solution was added. The entire reaction mixture was incubated in complete darkness for $30 \mathrm{~min}$, and thereafter, its absorbance was read at $517 \mathrm{~nm}$. The results were compared with ascorbic acid, which is a standard antioxidant equivalent. Percentage radical scavenging (\%RS) activity was calculated using the formula:

$\% \mathrm{RS}=\left(\left[A_{\mathrm{br}}-A_{\mathrm{ar}}\right] / A_{\mathrm{br}}\right) \times 100$

where $A_{\mathrm{br}}$ is the absorbance before reaction and $A_{\mathrm{ar}}$ is the absorbance after the reaction has taken place. The results of the comparative analysis of the standard and Amentoflavone were shown in Fig. 3.

\section{Cytotoxicity by MTT assay}

HepG2 cells were cultured in Dulbecco's modified medium (DMEM) supplemented with glutamine $(0.6 \mathrm{~g} / \mathrm{l})$, gentamicin $(25 \mathrm{mg} / \mathrm{ml})$, and $10 \%$ fetal calf serum at $37{ }^{\circ} \mathrm{C}$ and humidified with $5 \% \mathrm{CO}_{2}$. Cells were plated in a 96-well plate $\left(10^{5}\right.$ cells/well for adherent cells or $0.3 \times 10^{6}$ cells/well for suspended cells in $100 \mu \mathrm{l}$ of medium). After $24 \mathrm{~h}$, the standard and compound $(6,12,25,50$, and $100 \mu \mathrm{g} / \mathrm{ml})$ dissolved in DMSO (1\%) was added to each well and incubated for $96 \mathrm{~h}$. At the end of $96 \mathrm{~h}$ incubation, the medium in each well was replaced with fresh medium containing $0.5 \mathrm{mg} / \mathrm{ml}$ of MTT. The growth of HepG2 cells was quantified by the ability of living cells to reduce the yellow dye MTT to a blue formazan product. Four hours later, the formazan product of MTT reduction was dissolved in DMSO and absorbance was measured at $570 \mathrm{~nm}$ (Ferrari et al. 1990). The change in color indicates the cell viability and toxicity. The absorbance was noted down at $570 \mathrm{~nm}$, and the $\%$ cell survival was calculated using the following formula:

$\%$ Cell survival $=\left(\mathrm{OD}_{\mathrm{T}} / \mathrm{OD}_{\mathrm{C}}\right) \times 100$.

$\mathrm{OD}_{\mathrm{T}}$ and $\mathrm{OD}_{\mathrm{C}}$ are the mean absorbance of the treated and the control cells, respectively. The concentration of the extract that caused a half-maximal inhibition of cell proliferation $\left(\mathrm{IC}_{50}\right)$ was determined obtained from a semi-log plot of the concentrations against the percentage of cell survival. 


\section{Results and discussion}

For the foremost time, the present research investigation afforded Amentoflavone, from the leaves of Cassia fistula. The yielded Amento flavonone is semisolid (20 mg), and

(a)<smiles>O=C1CC(c2ccc(O)c(-c3c(O)cc(O)c4c(=O)cc(-c5ccc(O)cc5)oc34)c2)Oc2cc(O)cc(O)c21</smiles>

(b)

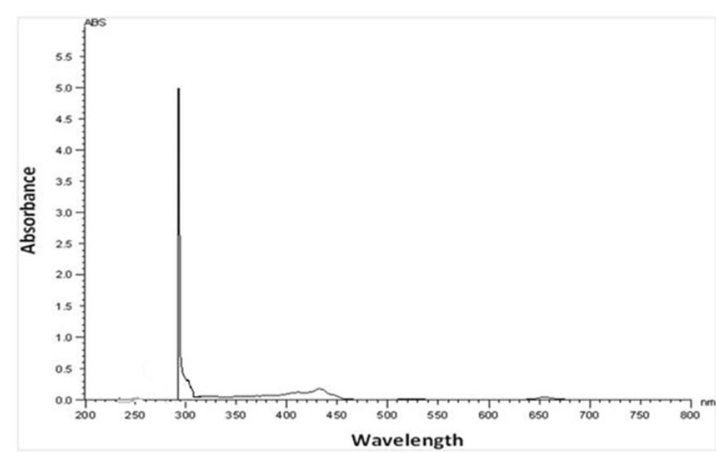

(c)

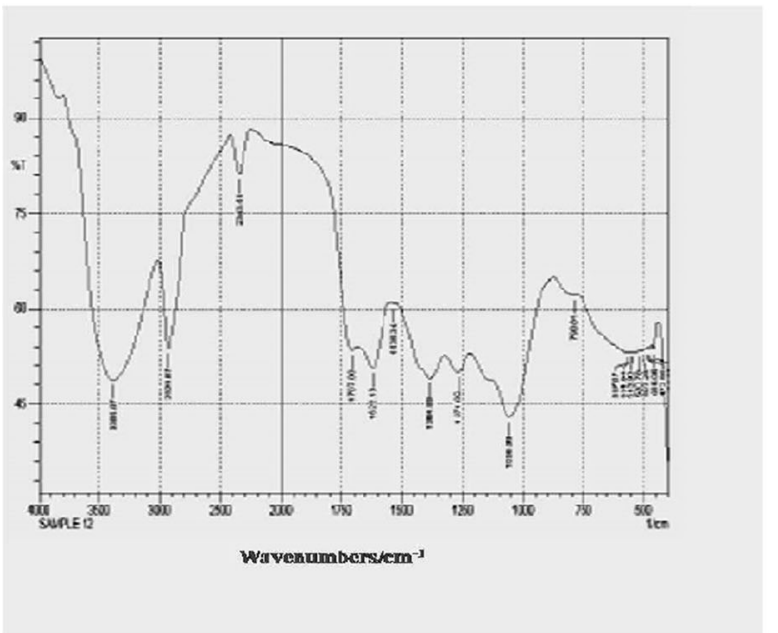

Fig. 1 a Structure of Amentoflavone (biflavonoid) elucidated by NMR; b UV visible spectrum of Amentoflavone extracted from the ethanolic extracts of Cassis fistula L.; c FTIR spectrum of isolated Amentoflavone from the ethanolic leaf extract of Cassia fistula L. in the characterization of the isolated molecules was analyzed using multispectroscopic techniques, such as UV-Vis, FTIR, and NMR (Fig. 1). Further HPLC analysis was carried out, Amento flavonone present in the sample was identified by matching the retention time against those of

(d)

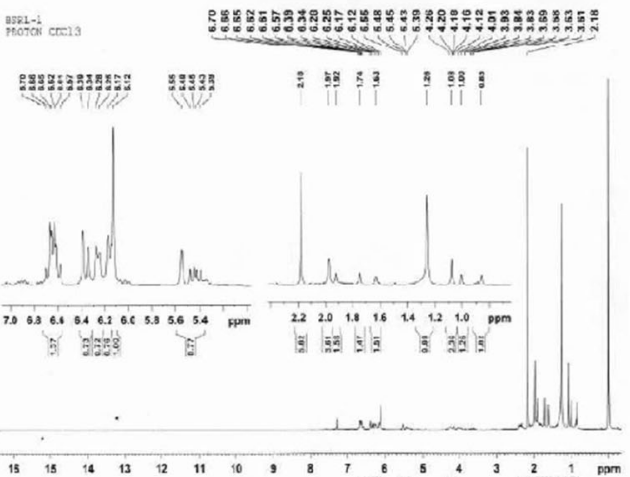

(e)

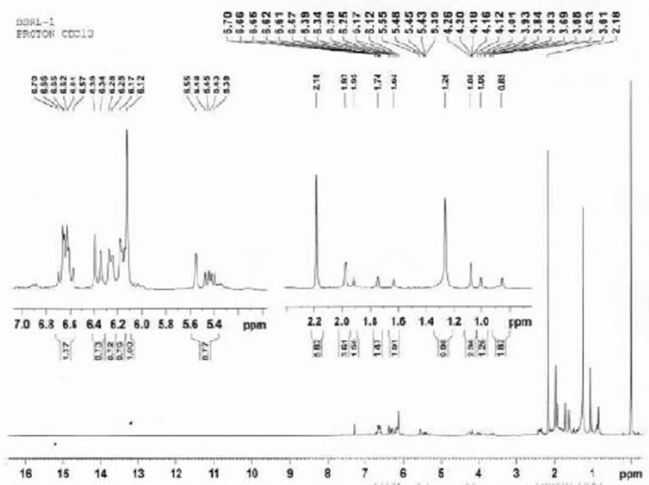

(f)

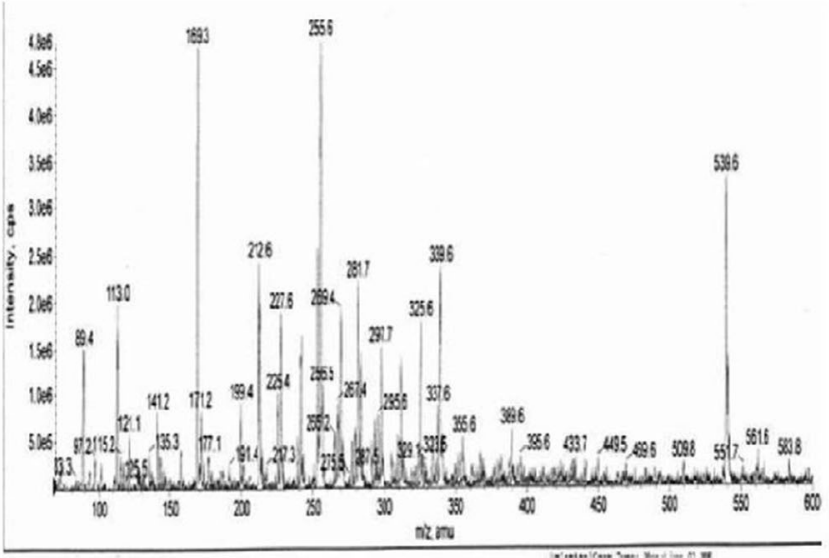

the $4000-400 \mathrm{~cm}^{-1}$ region; d Structure elucidation by $\mathrm{C}^{13} \mathrm{NMR}$ spectra of isolated compound; e Structure elucidation by NMR for isolated compound (proton donor atom); and $\mathbf{f}$ Structure elucidation by NMR spectra for isolated compound (MS) 
Fig. 2 HPLC data of a standard and $\mathbf{b}$ isolated Amentoflavone
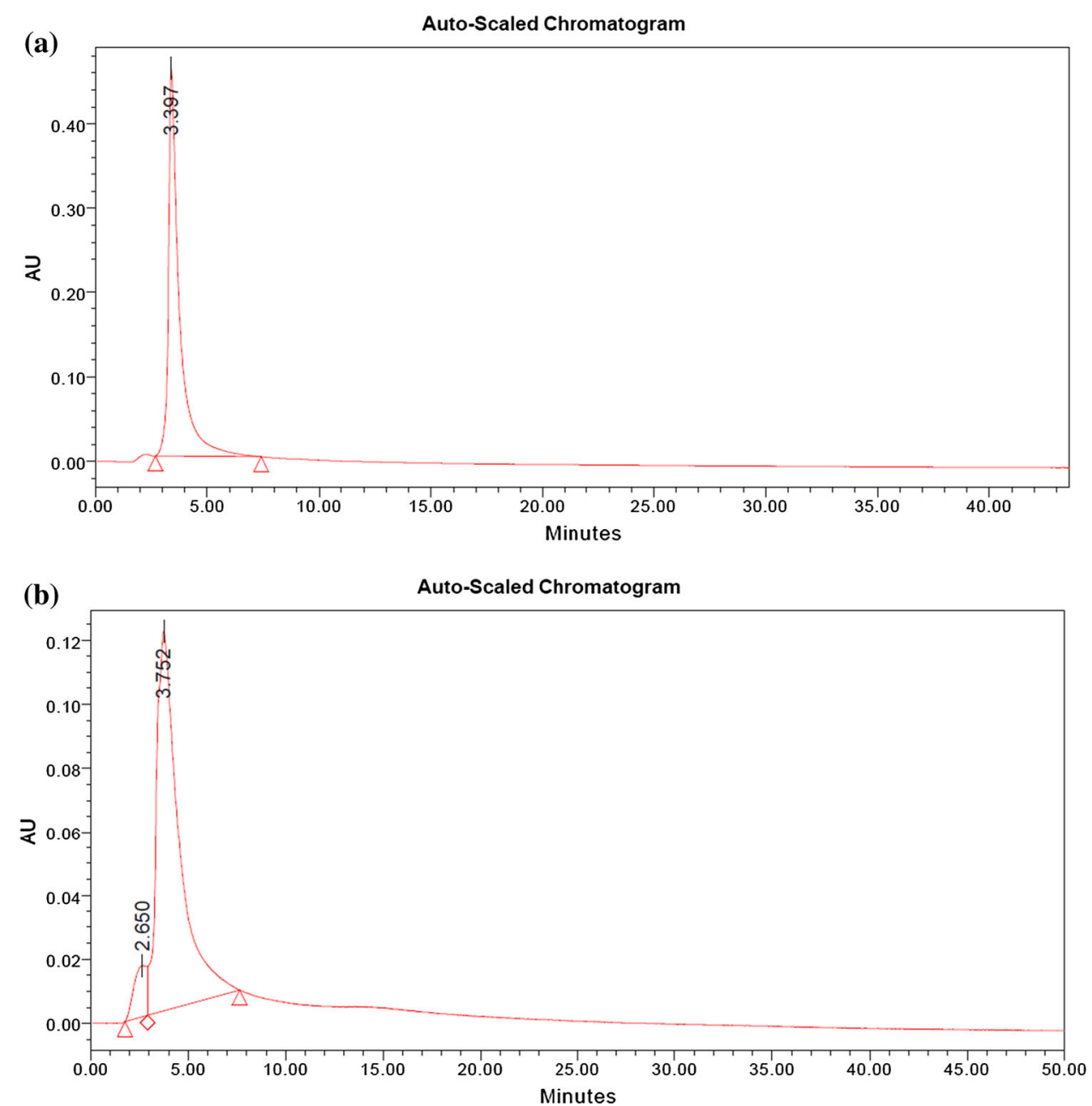

standard, and the content of Amentoflavone was determined using calibration curve. The data analysis was done using the Empower 2 software, and the results of the standard and novel compound are shown in Fig. 2. Thus, for the first time, we report the presence of Amentoflavone in Cassia fistula leaves. Literature review showed Amentoflavone to be a potential bioactive compound. Amentoflavone is an irreversible inhibitor of lymphocyte proliferation (Guruvayoorappan and Kuttan 2008), an inhibitor of phospholipase, and an inhibitor of nitric oxide synthase in macrophages (Woo et al. 2005). Leaves of the species appear to be potential sources for Amento flavone. They can be extracted in sufficient amounts from these species, as they are prevalent in most of the places. Reactive oxygen species and free radicals are unstable, highly reactive molecules generated during normal biochemical metabolism and pathological conditions which damage biological macromolecules, such as DNA, protein, lipids ultimately leading to apoptosis (Francis et al. 2010, Jayaprakasha et al. 2006). Intake of antioxidants plays an important role in body's defense mechanism to defend against free radicals and ROS (Rimm et al. 1993). Destroying activity of free radicals is sheltered by antioxidant by scavenging (Siva et al. 2011). The hunt for safe and potent phyto-therapeutic with antioxidant property is on high demand (Bhakta and Siva 2012). Furthermore, the therapeutic efficacy of the Amentoflavone was studied by DPPH and cytotoxic studies (Fig. 3). Dose-dependent antioxidant and cytotoxic activity was exhibited by Amentoflavone. The $\mathrm{IC}_{50}$ value of Amentoflavone was determined to be $29.7 \mu \mathrm{g} / \mathrm{ml}$. Thus, Amentoflavone inactivates the singlet oxygen and scavenge the free radicals. The cytotoxicity of HepG2 cells upon Amentoflavone treatment was observed. Dose-dependent cytotoxicity was observed with an $\mathrm{IC}_{50}$ value of $25.3 \mu \mathrm{g} / \mathrm{ml}$. Thus, the potent therapeutic efficacy of Amentoflavone is revealed. 

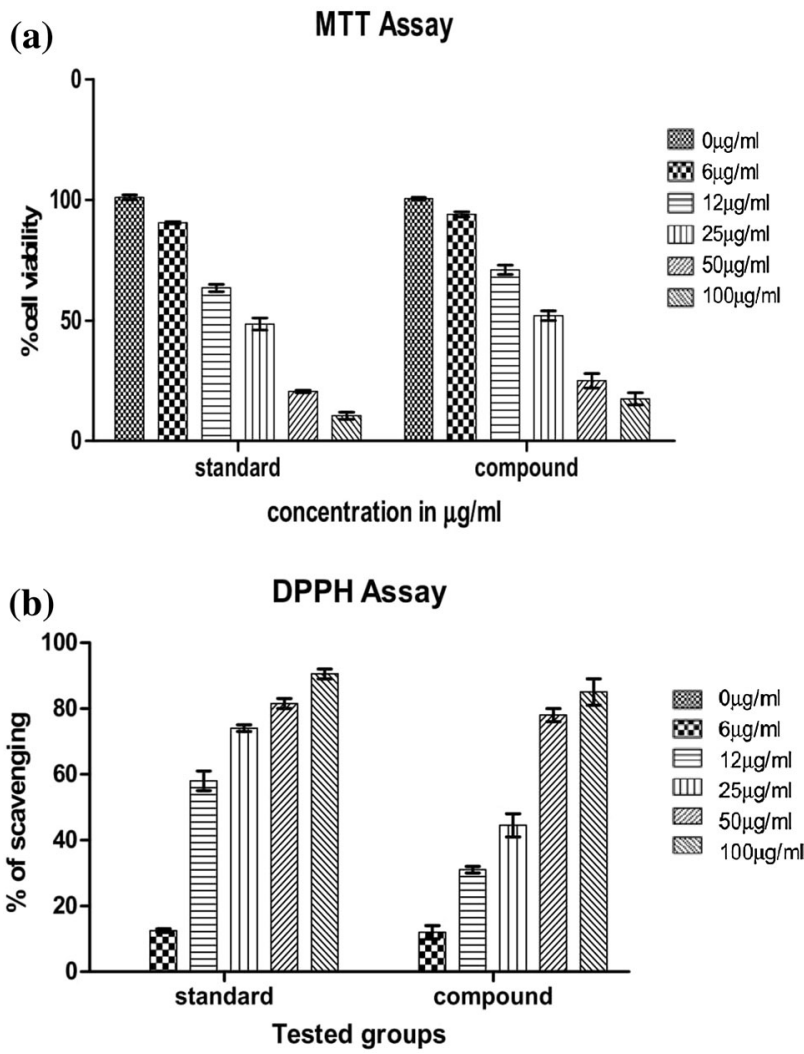

Fig. 3 Comparative study of the cytotoxicity and antioxidant activity of the novel and standard Amentoflavone by a DPPH and b MTT assay

\section{Conclusion}

Hence, for the foremost time, it has been reported that $C$. fistula $\mathrm{L}$. can be considered as a potential source for Amentoflavone. The findings from this work revealed the provided proof for the functional value of the medicinal potential of Cassia fistula L. However, further study should be carried out to determine the possible mechanisms of action.

Acknowledgements The author expresses a deep sense of gratitude to the management of VIT University for all the support, assistance, and constant encouragement provided by them to carry out this work.

\section{Compliance with ethical standards}

Conflict of interest The authors declare that they have no conflict of interest.

Open Access This article is distributed under the terms of the Creative Commons Attribution 4.0 International License (http:// creativecommons.org/licenses/by/4.0/), which permits unrestricted use, distribution, and reproduction in any medium, provided you give appropriate credit to the original author(s) and the source, provide a link to the Creative Commons license, and indicate if changes were made.

\section{References}

Bahorun T, Neergheen VS, Aruoma I (2005) Phytochemical constituents of Cassia fistula. Afr J Biotechnol 4:1530-1540

Bhakta D, Siva R (2012) Amelioration of oxidative stress in biomembranes and macromolecules by non-toxic dye from Morinda tinctoria (Roxb.) roots. Food Chem Toxicol 50:2062-2069

Bhalodia NR, Nariya PB, Acharya RN, Shukla VJ (2012) In vitro antibacterial and antifungal activities of Cassia fistula Linn. fruit pulp extracts. Ayu 33:123-129

Das S, Sarma G, Barman S (2008) Hepatoprotective activity of aqueous extract of fruit pulp of Cassia fistula (AFCF) against carbon tetrachloride (CCL4) induced liver damage in albino rats. J Clin Diagn Res 2:1133-1138

Ferrari M, Fornasiero MC, Isetta AM (1990) MTT colorimetric assay for testing macrophage cytotoxic activity in vitro. J Immunol Methods 131(2):165-172

Francis MA, Emmanuel T, Peter NU (2010) Free radical scavenging activity and phenolic contents of Anthocleista djalonensis (Loganiaceae) leaf extract. Int J Biol Chem Sci 4:2314-2323

Guruvayoorappan C, Kuttan G (2008) Inhibition of tumor specific angiogenesis by amentoflavone. Biochemistry (Mosc) 73:209-218

Jayaprakasha GK, Negi PS, Jena BS (2006) Antioxidative and antimutagenic activities of the extracts from the rinds of Garcinia pedunculata. Innov Food Sci Emerg Technol 7:246-250

Ohinishi M, Morishta H, Iwahashi H, Toda S, Shirataki Y, Kimura M, Kido R (1994) Inhibitory effects of chlorgenic acids on linoleic acid peroxidation and hemolysis. Phytochemistry 36:579-583

Panda SK, Padhi LP, Mohanty G (2011) Antibacterial activities and phytochemical analysis of Cassia fistula (Linn.) leaf. J Adv Pharm Technol Res 2:62-67

Rahmani AH, Aly SM (2015) Nigella sativa and its active constituents thymoquinone shows pivotal role in the diseases prevention and treatment. Asian J Pharm Clin Res 8:48-53

Rahmani AH, Aly SM, Ali H, Babiker AY, Srikar S, Khan AA (2014a) Therapeutic effects of date fruits (Phoenix dactylifera) in the prevention of diseases via modulation of anti-inflammatory, antioxidant and anti-tumour activity. Int J Clin Exp Med 7:483-491

Rahmani AH, Shabrmi FM, Aly SM (2014b) Active ingredients of ginger as potential candidates in the prevention and treatment of diseases via modulation of biological activities. Int $\mathbf{J}$ Physiol Pathophysiol Pharmacol 6:125-136

Rajagopal PL, Premaletha K, Kiron SS, Sreejith KR (2013) Phytochemical and pharmacological review on Cassia fistula Linn. the golden shower. Int J Pharm Chem Biol Sci 3:672-679

Rimm EB, Stamfer MJ, Ascherio A, Giovanncci E, Colditz GA, Willet WC (1993) Vitamin E consumption and risk of coronary heart diseases in men. N Engl J Med 328:1450-1456

Senthil Kumar M, Sripriya R, Vijaya Raghavan H, Sehgal PK (2006) Wound healing potential of Cassia fistula on infected albino rat model. J Surg Res 131:283-289

Siva R (2007) Status of natural dyes and dye yielding plants in India. Curr Sci 92:916-925

Siva R, Palackan MG, Maimoon L, Geetha T, Dipita B, Balamurugan P, Rajanarayanan S (2011) Evaluation of antibacterial, antifungal, and antioxidant properties of some food dyes. Food Sci Biotechnol 20:7-13

Vasudevan DT, Dinesh KR, Gopalkrishnan S, Sreekanth SK, Shekar S (2009) The potential of aqueous and isolated fraction from leaves of Cassia fistula Linn as antibacterial agent. Int $\mathbf{J}$ Chem Sci 7:2363-2367

Woo ER, Lee JY, Cho IJ, Kim SG, Kang KW (2005) Amentoflavone inhibits the induction of nitric oxide synthase by inhibiting NF$\mathrm{kB}$ activation in macrophages. Pharmacol Res 51:539-546 